\title{
HIGH-STRAIN TESTS ON LEAD-RUBBER BEARINGS FOR EARTHQUAKE LOADINGS
}

\author{
R. G. Tyler* and W. H. Robinson**
}

\section{ABSTRACT}

Dynamic tests on two lead-rubber bearings, $280 \times 230 \times$ $113 \mathrm{~mm}$, are described in which a dynamic actuator was used to apply shear displacements of \pm 10 to $\pm 140 \mathrm{~mm}$ at frequencies of 0.1 to $3 \mathrm{~Hz}$, giving shear strains in the rubber of up to $\pm 200 \%$. The weight of the structure on the bearing was applied by a vertical jacking system and ranged from 35 to $455 \mathrm{kN}$. Sequences of cycles were performed to simulate earthquake conditions and force-displacement hysteresis loops were obtained.

It was concluded that at strains approaching $200 \%$ in the rubber, the force-displacement hysteresis loop could be represented by the linear elastic slope of the rubber component plus a rectangle appropriate to the plastic shear of the lead, with some rounding of the corners of the hysteresis loop. There was a decrease in the area of the hysteresis loop of $20 \%$ after six cycles at $1 \mathrm{~Hz}$ with a maximum shear strain of $125 \%$ in the rubber; but recovery followed within minutes. In one bearing an attempt was made to locally confine the lead by screwing external plates to the first internal plate within the bearing at the top and the bottom, but no difference in performance between the two bearings was noted. The scope of the tests indicated that, with peak strains in excess of $100 \%$ in the rubber, the bearings would continue to perform satisfactorily for a sequence of very large earthquakes.

\section{INTRODUCTION}

The use of laminated rubber bearings, with damping provided by lead plugs, is now an accepted technology throughout the world for the base isolation of buildings and bridge decks following the pioneering work in New Zealand culminating in the consiruction of the William Clayton Building in Wellington (1-8). Previous tests on leadrubber bearings at PEL(1-3) were carried out using a converted bulldozer for producing shear displacements at $\sim_{1} \mathrm{~Hz}$, but this technique was inconvenient from the point of view of varying the stroke and frequency of loading. The tests described in this paper were carried out using the Dartec dynamic test equipment in the new test hall. This equipment enabled the stroke and frequency to be readily controlled and also allowed simulated earthquake motions to be applied to the bearings.

Initial research on using lead for hysteretic damping started with the development of the lead extrusion damper, a device in which lead is extruded back and forth through an orifice $(10,11)$. The extrusion damper behaves like a plastic solid or coulomb damper, is able to be built with a long stroke $(> \pm 300 \mathrm{~mm})$ and is capable of operating continuously for thousands of cycles; twelve of these dampers have been installed in two overpass bridges in wellington. However, like most of the steel hysteresis dampers, the extrusion device operates only in one direction and is expensive to make. The lead-rubber bearing has the great advantages of being

* Head of Engineering Seismology Section

* Head of Physics Division, Physics and Engineering Laboratory, DSIR, I,ower Hutt

ULLETIN OF THE NEW ZEALAND NATION relatively cheap, of supporting the structure and providing a damping force in all directions in the horizontal plane, and having a satisfactory performance and life. However, it must be noted that the leadrubber bearing represents a sound economic solution to the problem of base isolation and as such is designed to withstand the effects of a limited number of major earthquakes occurring in sequence.

\section{THE BEARINGS TESTED}

Two bearings were supplied as part of a production run for the Devils Creek Bridge, State Highway 7, Reefton, South Island, New Zealand. They were $280 \times 230$ $\mathrm{x} 113 \mathrm{~mm}$ in overall dimensions, supplied with a $75 \mathrm{~mm}$ diameter cylindrical hole right through the centre of the bearing (Figure 1). Separate lead plugs were supplied to be fitted as required. The details of the bearings supplied by the manufacturers, Empire Rubber Mills of Christchurch, are as follows:

\section{Manufacturer's Details}

Completely rubber enclosed vulcanised rubber-on-metal bonded bearings.

Size $280 \times 230 \times 113 \mathrm{~mm}$ with central hole $75 \mathrm{~mm}$ diameter (Figure 1 ).

Top and bottom cover layers of rubber

$$
2 \times 5 \mathrm{~mm}=10 \mathrm{~mm}
$$

Inner layers of rubber

$$
10 \times 7 \mathrm{~mm}=70 \mathrm{~mm}
$$

Embedded steel plates 

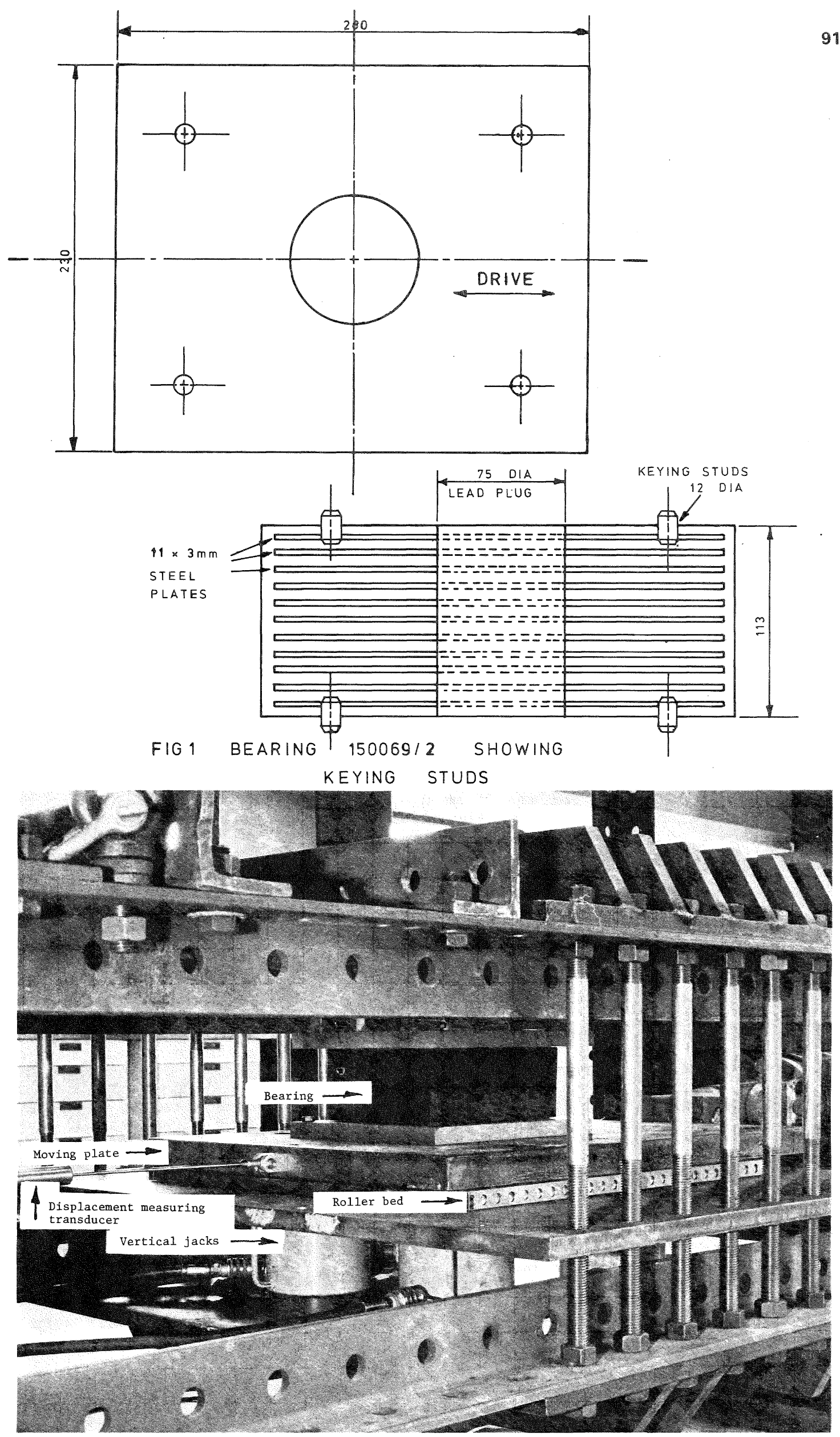

Fig.2 Test rig with rubber bearing in position. 
Total thickness $=113 \mathrm{~mm}$

Side cover rubber thickness $=7 \mathrm{~mm}$

Internal steel plates $=266 \times 216 \mathrm{~mm}$

Calculated capacity $\left(\mathrm{P}_{50}\right)$, with $75 \mathrm{~mm}$ hole unfilled $=280 \mathrm{kN}$ with $\pm 40 \mathrm{~mm}$ allowable shear movement (to $\mathrm{BE} 1 / 76$ )

Calculated capacity with zero shear movement $\left(P_{O}\right)=460 \mathrm{kN}$ (to $\mathrm{BE} \mathrm{1/76)}$

Compressive stiffness $=96 \mathrm{kN} / \mathrm{mm} \pm 20 \%$

Rated load for stiffness in compression $=460 \mathrm{kN}$

Shear stiffness $=0.58 \mathrm{kN} / \mathrm{mm} \pm 20 \%$

Rated load for tests in shear $=280 \mathrm{kN}$

Rated shear for test on stiffness in shear $=35 \mathrm{~mm}(50 \%)$

Bearing numbers were $\mathrm{A} 150069 / 1$ and A150069/2

\section{Test for Compressive Stitfness}

The compressive stiffness of bearing A150069/2 without the lead plug was determined as $61 \mathrm{kN} / \mathrm{mm}$ up to a load of $250 \mathrm{kN}$, as compared with the manufacturer's calculation above of $96 \mathrm{kN} / \mathrm{mm}$ for a plain multilayer bearing with no hole.

\section{TEST FACILITY}

\section{The Test Rig}

The Dartec dynamic actuator of $200 \mathrm{kN}$ capacity and a sinusoidal stroke of $\pm 150 \mathrm{~mm}$ was employed for the tests in the rig shown in Figure 2. While ideally a pair of bearings would be tested together, this effectively doubles the load on the ram and the number of bearings as required; accordingly a layer of close-spaced rollers $25 \mathrm{~mm}$ diameter was located on one side of the sliding plate. A set of four rams, each of 1,000 $\mathrm{kN}$ capacity, acting vertically below the rubber bearing, was used to simulate the static dead weight of the structure. The horizontal force was recorded using a load cell while a linear voltage displacement transducer, shown on the left of Figure 2, provided a measure of the horizontal displacement.

\section{Test with Rollers Only}

The first tests were carried out with two sets of rollers, with one set above the horizontal sliding plate and one below, in order to determine their friction characteristics for a range of vertical jack loadings. The frequency of test was $1 \mathrm{~Hz}$, but similar results were obtained at $0.1 \mathrm{~Hz}$.

Approximately rectangular hysteresis loops were obtained for the horizontal force displacement curve. The friction force $\mathrm{F}_{\mathrm{f}}$, to be deducted from the hysteresis loops obtained later for a rubber bearing plus one set of rollers, was found to be about $0.7 \%$ of the vertical load over a range of vertical loads of 105 to $455 \mathrm{kN}$.

\section{TESTS ON BEARING No $150069 / 2$}

The bearing was spigotted to the fixed top platen of the test machine and to the horizontal moving plate as shown in Figure 1. with a set of rollers beneath as in Figure 2 .
Tests Without the Lead Plug

Tests were carried out in shear at $1 \mathrm{~Hz}$ for a range of vertical loads within the rated vertical load of the bearing at zero shear $\left(\mathrm{P}_{0}\right)$, and for strokes up to $\pm 70 \mathrm{~mm}$, corresponding to $\pm 100 \%$ shear strain in the rubber. The results are shown in Figure 3. The response is essentially elastic, remembering that part of the loop area is attributable to friction in the roller assembly underneath the moving plate.

Following the tests at $1 \mathrm{~Hz}$, more tests were carried out at $\pm 100 \%$ shear strain for frequencies of $0.1,0.3$ and $1 \mathrm{~Hz}$ at the rated vertical load for $50 \%$ shear strain in the rubber $\left(\mathrm{P}_{50}\right)$. At $3 \mathrm{~Hz}$ the pumps could not keep up with the required jack response and there was loss of stroke length. The loop obtained at $0.1 \mathrm{~Hz}$ is also shown in Figure 3. There is a $40 \%$ reduction in the loop area as compared with that at $1 \mathrm{~Hz}$, but again the response was essentially elastic. The curve for $0.3 \mathrm{~Hz}$ was intermediate between those at $1 \mathrm{~Hz}$ and $0.1 \mathrm{~Hz}$.

\section{Insertion of Lead Plug}

The lead plug supplied just fitted the hole in the bearing and was eased into position in such a way that the lead projected out of the bearing on each of the top and bottom faces by $3 \mathrm{~mm}$. The bearing was then placed in a hydraulic press and the lead squeezed down flush with the rubber on the top and bottom surfaces.

\section{Tests With Lead Plug in Position}

The various tests on the lead-rubber bearing are summarised in Table 1.

Two-cycle tests: Two-cycle tests were carried out for strains of $\pm 25, \pm 50, \pm 75$ and $\pm 100 \%$ in the rubber for each of the vertical loads in the following order: $35 \mathrm{kN}$, $105 \mathrm{kN}, 175 \mathrm{kN}, 280 \mathrm{kN}\left(\mathrm{P}_{50}\right), 350 \mathrm{kN}$ and $455 \mathrm{kN}\left(\mathrm{P}_{\mathrm{O}}\right)$, at a frequency of $1 \mathrm{~Hz}$. TO establish uniform conditions for each test, there was an interval of three minutes between each pair of cycles, to give the lead time to cool before the next test and to recover its mechanical properties. The effect of consecutive cycling was studied later.

The large number of individual hysteresis loops obtained from the two-cycle tests were, for each vertical load, combined together (Figure 4). The value of combining the loops for a particular vertical load on one graph for purposes of comparison were recognised later when the set of hysteresis loops shown in Figure 5 was obtained for strain cycles of up to a nominal $\pm 200 \%$ in the rubber at load $\mathrm{P}_{50}$. The frequency was initially $1 \mathrm{~Hz}$, but the loops for $\pm 125 \%$ and $\pm 150 \%$ rubber strain indicated that the limit of the pumps had been reached. The loops at \pm 175 and $\pm 200 \%$ strain were thus completed at $0.5 \mathrm{~Hz}$.

Decay Test: The effect of a sudden drop in vertical load was examined by starting to cycle at $\pm 75 \%$ shear strain in the rubber at a vertical load of $\mathrm{P}_{\mathrm{O}}$ and suddenly releasing the oil pressure to the vertical jacks while at the same time continuing to cycle in the horizontal direction at $1 \mathrm{~Hz}$. The effect is 
TABLE 1

Bearing No $150069 / 2$

Numbers of cycles performed with lead plug in bearing.

(At $1 \mathrm{~Hz}$ unless otherwise indicated. The date given is day and month for 1983.)

\begin{tabular}{|c|c|c|c|c|c|c|c|c|c|c|c|c|c|}
\hline \multirow{3}{*}{$\begin{array}{c}\text { Vertical } \\
\text { load } \\
(\mathrm{kN}) \\
\mathrm{P}\end{array}$} & \multicolumn{13}{|c|}{ Strain in rubber ( \pm percent) } \\
\hline & \multicolumn{2}{|r|}{25} & \multicolumn{2}{|r|}{50} & \multicolumn{2}{|r|}{75} & \multicolumn{2}{|c|}{100} & 125 & 150 & 175 & \multicolumn{2}{|r|}{200} \\
\hline & No. & Date & No. & Date & No. & Date & No. & Date & No. Date & No. Date & No. Date & No. & Date \\
\hline 35 & & & & & & $6 / 10$ & & $18 / 10$ & & & & & \\
\hline 70 & & & & & & $6 / 10$ & & $18 / 10$ & & & & & \\
\hline 105 & 2 & $6 / 10$ & 2 & $6 / 10$ & 2 & $6 / 10$ & $\begin{array}{l}2 \\
2 \\
2\end{array}$ & $\begin{array}{c}6 / 10 \\
18 / 10 \\
18 / 10^{\star}\end{array}$ & & & & & \\
\hline 175 & 2 & $6 / 10$ & 2 & $6 / 10$ & & $\begin{array}{r}6 / 10 \\
18 / 10\end{array}$ & 2 & $18 / 10$ & & & & & \\
\hline $\begin{array}{c}280 \\
\left(P_{50}\right)\end{array}$ & & $\begin{array}{r}6 / 10 \\
18 / 10\end{array}$ & $\begin{array}{l}2 \\
1\end{array}$ & $\begin{array}{r}6 / 10 \\
18 / 10\end{array}$ & $\begin{array}{l}2 \\
1\end{array}$ & $\begin{array}{r}6 / 10 \\
18 / 10\end{array}$ & $\begin{array}{l}2 \\
1\end{array}$ & $\begin{array}{r}6 / 10 \\
18 / 10\end{array}$ & $\begin{array}{ll}2 & 18 / 10 \\
1 & 18 / 10\end{array}$ & $118 / 10$ & $118 / 10^{\dagger}$ & $\begin{array}{l}1 \\
5 \\
5\end{array}$ & $\begin{array}{l}18 / 10^{\dagger} \\
18 / 10^{\dagger} \\
18 / 10^{\dagger}\end{array}$ \\
\hline 350 & 2 & $6 / 10$ & 2 & $6 / 10$ & 2 & $6 / 10$ & 2 & $18 / 10$ & & & & & \\
\hline $\begin{array}{r}455 \\
\left(\mathrm{P}_{\mathrm{O}}\right)\end{array}$ & & $6 / 10$ & 2 & $6 / 10$ & 2 & $6 / 10$ & 2 & $18 / 10$ & & & & & \\
\hline $\begin{array}{l}\text { Total } \\
\text { Cycles }\end{array}$ & 12 & & 11 & & 19 & & 19 & & 1 & 1 & 1 & 10 & \\
\hline
\end{tabular}

Total 75 cycles

* At $0.1 \mathrm{~Hz}$

+ At $0.5 \mathrm{~Hz}$ 


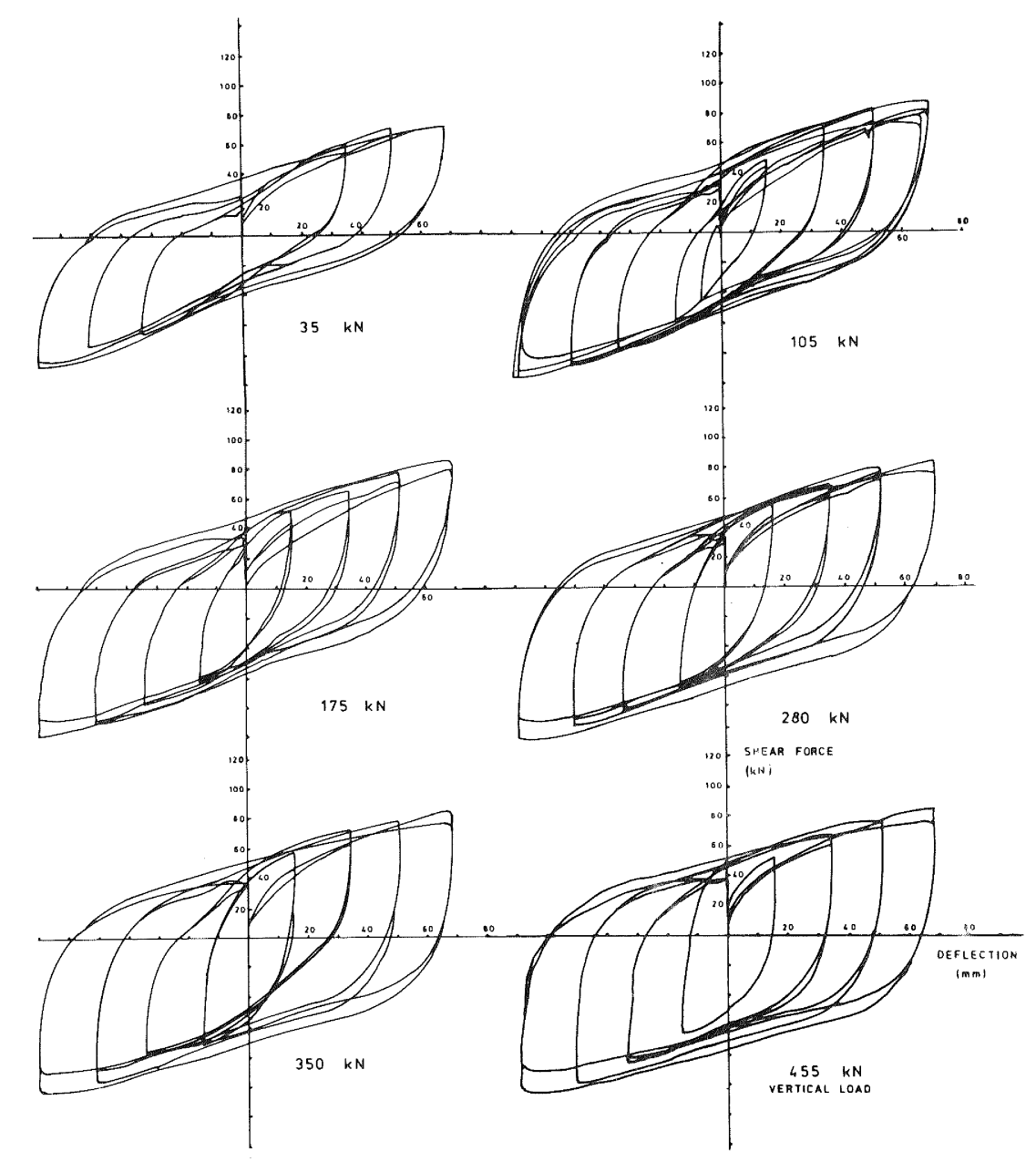

Fig. 4: Shear force/displacement hysteresis loops for a frequency of $1 \mathrm{~Hz}$ for a range of vertical loads (Bearing 15009/2)

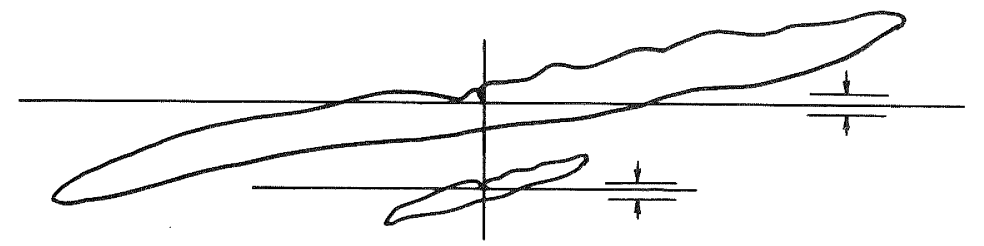

LOAD ON BEARING $=450 \mathrm{kN}$

HORIZONTAL
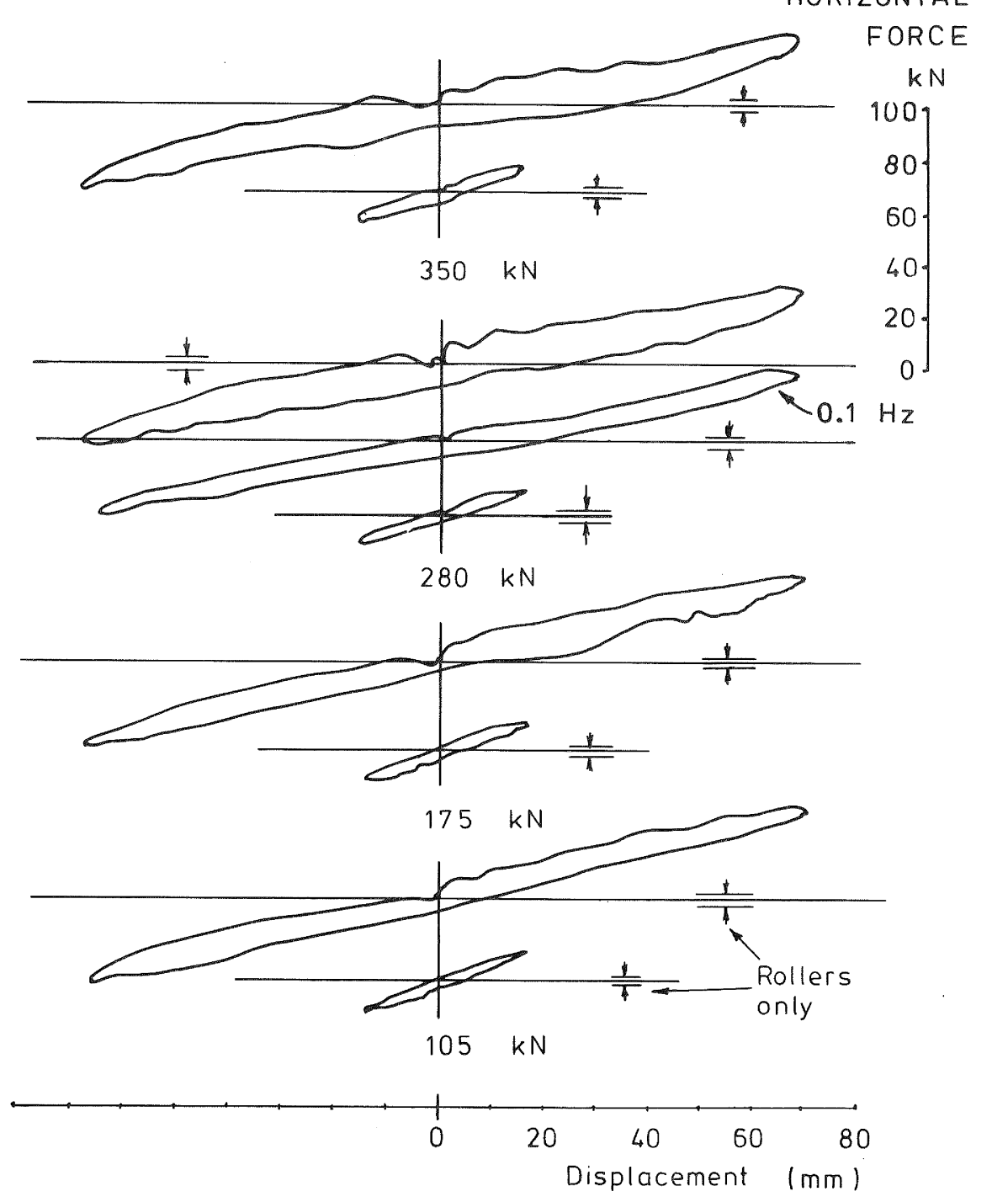

nb. all curves $1 \mathrm{~Hz}$ except where stated

Fig. 3 Shear force/displacement loops without lead plug. 
important since a building rocking under earthquake attack will experience oscillating vertical loads on its bearings, particularly at its corners, and the response in terms of the hysteresis loop needs to be established. The decay in the loop area with diminishing vertical pressure is indicated in Figure 6 . The response to the sudden drop in vertical load was noted to be rapid, implying that the confining effect on the lead essentially arises via the elasticity of the rubber.

Five-cycle Tests: The oil supply delivered by the pumps was improved and testing of this bearing was completed with a set of 5 cycles at a frequency of $1 \mathrm{~Hz}$ and a nominal $\pm 200 \%$ shear strain in the rubber under the vertical load $P_{50}$ (Figure 7 ), followed by another set of 5 cycles 40 minutes later, during which time the jacking system was adjusted to be more nearly central below the bearing. There was little difference in shape between the two sets of loops, indicating complete recovery between tests. There was, however, a progressive reduction in depth of the loops from cycle to cycle for each test, from about $116 \mathrm{kN}$ for cycle 1 to $76 \mathrm{kN}$ for cycle 5, a 35 \% reduction. This reduction is attributed to the slight warming of the lead which causes a reduction in the shear stress for plastic deformation.

The slope of the upper and lower lines of the loops is seen to be within $\pm 20 \%$ of the slope for the bearing without a.lead plug (Figure 3 ), confirming that at large strains the loop is made up of the linear elastic stiffness of the bearing plus a rectangle appropriate to the plastic shearing of the lead with a shearing stress of about $11 \mathrm{MPa}$ for a vertical load of $280 \mathrm{kN}\left(\mathrm{P}_{50}\right)$ (Figure 17) for first cycles. This characterisation of the bearing hysteresis as being due to the elastic stiffness of the rubber plus plasticity of the lead can be regarded as the ultimate design condition for the bearing(3) and the value of the shear stress for plastic deformation of lead is comparable to the value of $10.5 \mathrm{MPa}$ obtained previously for lead plugs of 50 to $170 \mathrm{~mm}^{(3)}$.

Experiment upon this bearing was stopped on completion of these tests. The bearing had then completed 73 cycles, including 10 at a nominal $200 \%$ strain in the rubber (Table 1). The photograph (Figure $8)$ shows the bearing at $200 \%$ strain with the locating studs lifting clear of the bearing. It was concluded that locating studs should be nearer to the centre of the bearing in order to be effective at high strains. The appearance of the bearing after testing is shown in Figure 9 and the deformation of the lead plug, caused by a rolling frictional action against the steel platens, at the very high rubber strains imposed in the later tests, is indicated.

It is to be noted that even though the internal plates within the bearing were comparatively thin, the bearing at $200 \%$ shear strain was effectively being driven by two studs only, with considerable change in shape of the bearing. There would therefore appear to be a good argument for retaining comparatively thin, and thus compliant, plates in the bearing to engage the studs, rather than adopting the practice prevalent in the USA of bonding a heavy steel plate at the top and bottom of the bearing to which the structure is bolted. At high strains the rubber in such a bearing would tend to tear at the edges in order to change from a rectangular to an approximately elliptic shape (Figure 8).

\section{TESTS ON BEARING NO $150069 / 1$}

The object of the tests on this bearing was initially to establish whether the screwing of the first internal plate in the bearing at the top and bottom, to the machine platens, would improve the light-load performance by establishing a more definite confinement of the lead. Eight $8 \mathrm{~mm}$ countersunk screws were employed for this purpose in each platen (Figure 10). These screws also served as spigots to transfer the shear load. Since the thickness of the internal plates in the rubber bearing was only $3 \mathrm{~mm}$, there was no great thread length to be relied on.

\section{Tests without Lead Plug}

The hysteresis loops obtained in these tests were very similar to those obtained for the previous bearing, Figure 3, and accordingly are not reported. Testing was possible up to $2 \mathrm{~Hz}$ because of improved pump performance, when the hysteresis loop was again similar to that at $1 \mathrm{~Hz}$ given in Figure 3 .

\section{Insertion of Lead Plug}

For this bearing its lead plug was inserted by cooling in liquid nitrogen and dropping it into position in the bearing to allow it to expand to fill the hole. This procedure was a very convenient way of inserting the lead plug but there was no noticeable difference in later performance over the method employed for the previous bearing tested. The projection of the lead plug prior to pressing was again $3 \mathrm{~mm}$ at either end.

\section{Tests with Lead Plug in Position}

The various tests on this bearing are summarised in Table 2.

Two-cycle tests: Testing for the various vertical pressures and strokes generally followed that for the previous bearing with a pair of cycles being performed for each combination of pressure and stroke at three minute intervals for vertical loads up to $\mathrm{P}_{0}$ and rubber strains up to $\pm 100 \%$. (Tests carried out on 28 October 1983, Table 2.) Composite loops were obtained as previously by superimposing hysteresis loops in the drawing office for shear strains up to $100 \%$. Two further cycles were completed at $200 \%$ shear strain.

All the hysteresis loops obtained in the series of tests were similar to those obtained for the previous bearing tested (Figures 4 and 7 ) and are therefore not shown. Thus the use of the screwed top and bottom plate connection made essentially no difference to the bearing performance. In the last test at $200 \%$ strain all eight screws sheared off; the bearing was removed 


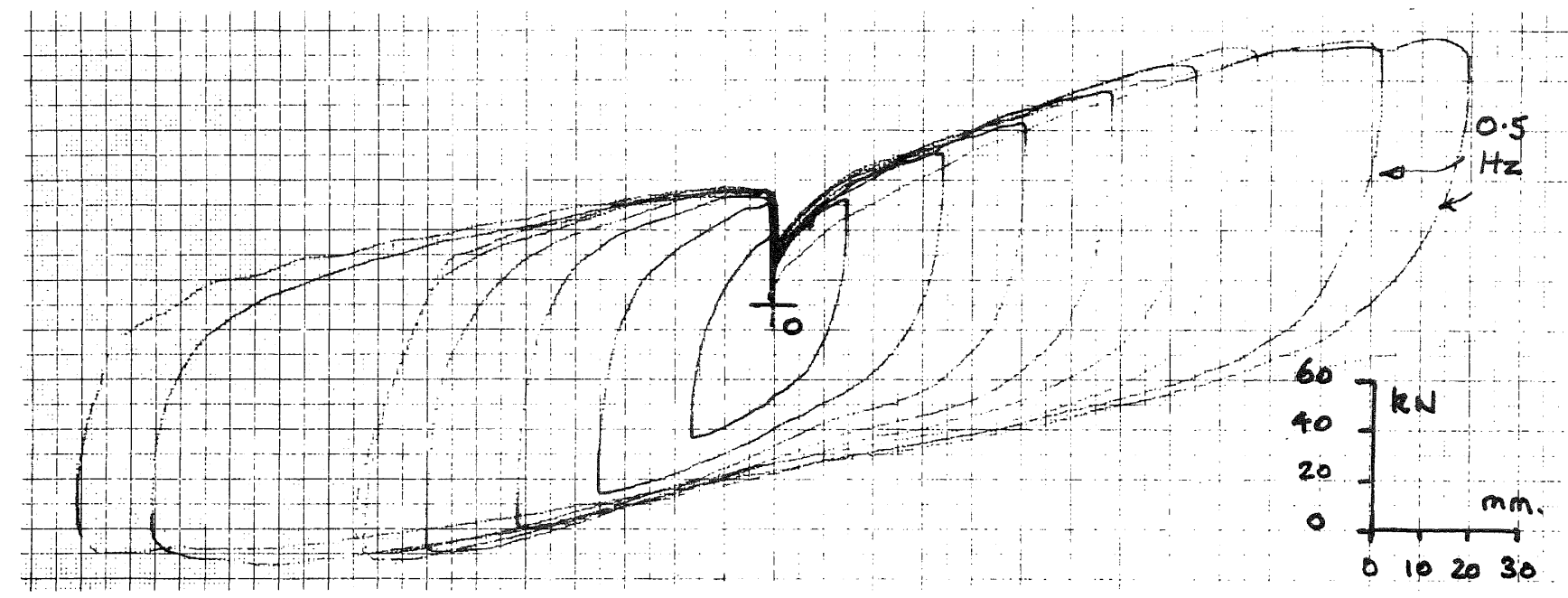

Fig. 5: Shear force/displacement hysteresis loops at a vertical load of $280 \mathrm{kN}$ (P50) up to a nominal strain in the rubber of $\pm 200 \%$. Frequency $1 \mathrm{~Hz}$ except where stated (Bearing 15009/2)

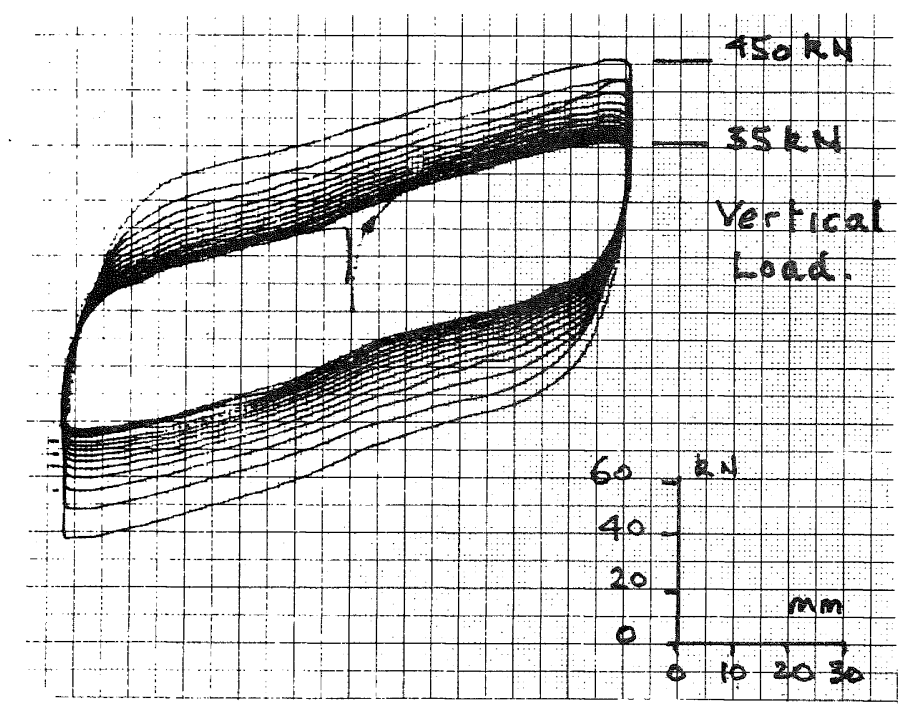

Fig. 6 (left): Effect of suddenly releasing oil pressure on vertical jacks while cycling at $1 \mathrm{~Hz}$ and $\pm 75 \%$ strain in rubber (Bearing 15009/2)

Fig. 7 (below): Five consecutive cycles to a nominal $\pm 200 \%$ strain in the rubber at $1 \mathrm{~Hz}$ (Bearing 15009/2)

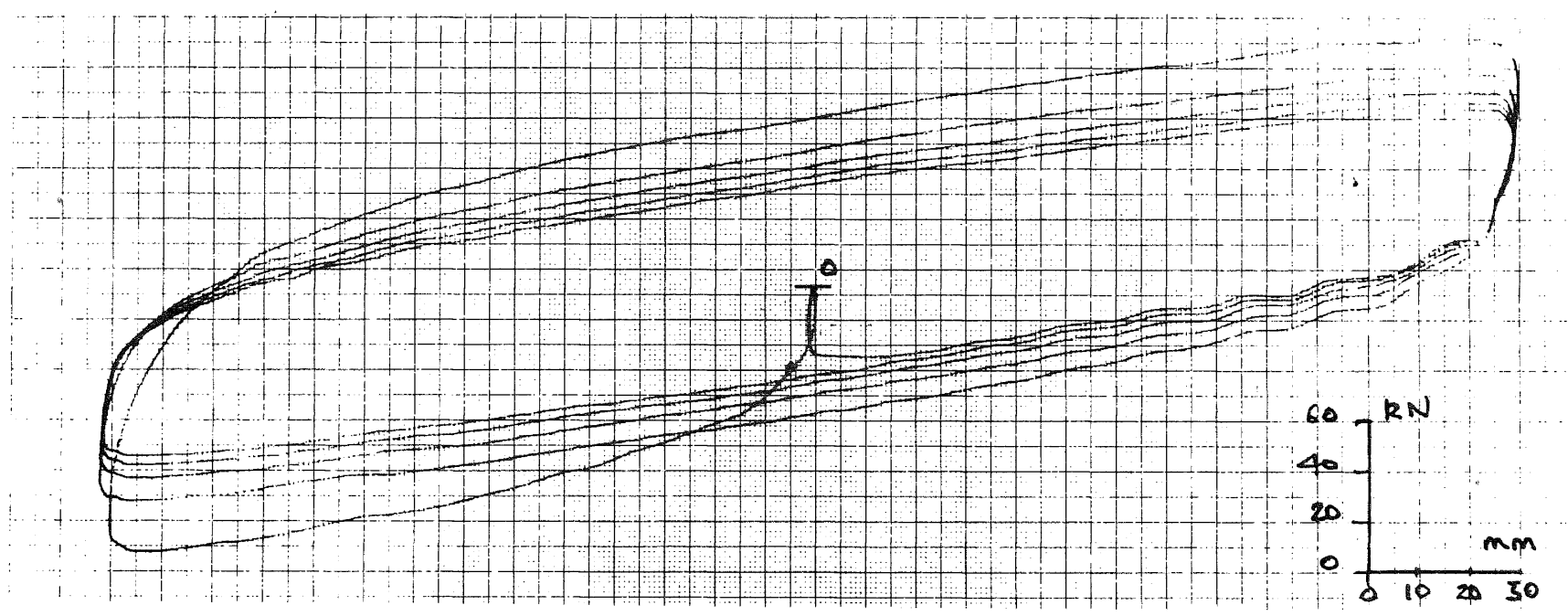


TABLE 2

Bearing No $150069 / 1$

Numbers of cycles performed with lead plug in bearing.

(Excluding the last runs of 60 and 45 minutes duration, and the simulated El Centro earthquake. At $0.1 \mathrm{~Hz}$ unless otherwise stated.

The date given is day and month for 1983.)

\begin{tabular}{|c|c|c|c|c|c|c|c|c|c|c|c|c|}
\hline \multirow{3}{*}{$\begin{array}{l}\text { Vertical } \\
\text { load } \\
(\mathrm{kN}) \\
\quad \mathrm{P}\end{array}$} & \multicolumn{12}{|c|}{ Strain in rubber $( \pm$ percent) } \\
\hline & & 25 & & 25 & & 75 & & 100 & & 25 & & 200 \\
\hline & No. & Date & No. & Date & No. & Date & No & Date & No. & Date & No, & Date \\
\hline 0 & 2 & $28 / 10$ & & & & & & & & & & \\
\hline 35 & & $\begin{array}{r}28 / 10 \\
3 / 11\end{array}$ & & $\begin{array}{r}28 / 10 \\
3 / 11\end{array}$ & 2 & $3 / 11$ & & $\begin{array}{r}28 / 10 \\
3 / 11\end{array}$ & 2 & $3 / 11$ & & \\
\hline 105 & & $\begin{array}{r}28 / 10 \\
3 / 11\end{array}$ & & $\begin{array}{r}28 / 10 \\
3 / 11\end{array}$ & 2 & $3 / 11$ & & $\begin{array}{r}28 / 10 \\
3 / 11\end{array}$ & 2 & $3 / 11$ & & \\
\hline 175 & 2 & $28 / 10$ & 2 & $28 / 10$ & & & & $28 / 10$ & & & & \\
\hline $\begin{array}{c}280 \\
\left(\mathrm{P}_{50}\right)\end{array}$ & & $\begin{array}{c}28 / 10 \\
2 / 11 \\
3 / 11 \star \\
3 / 11 \\
3 / 11+\end{array}$ & $\begin{array}{l}2 \\
1 \\
2 \\
2 \\
2\end{array}$ & $\begin{array}{l}28 / 10 \\
2 / 11 \\
3 / 11 \star \\
3 / 11 \\
3 / 11 \dagger\end{array}$ & & $\begin{array}{l}3 / 11 * \\
3 / 11\end{array}$ & & $\begin{array}{c}28 / 10 \\
2 / 11 \\
3 / 11 \star \\
3 / 11\end{array}$ & $\begin{array}{l}1 \\
2 \\
2\end{array}$ & $\begin{array}{l}2 / 11 \\
3 / 11 * \\
2 / 11\end{array}$ & 2 & $28 / 10$ \\
\hline 350 & 2 & $28 / 10$ & 2 & $28 / 10$ & & & & $28 / 10$ & & & & \\
\hline $\begin{array}{r}455 \\
\left(P_{O}\right)\end{array}$ & & $\begin{array}{r}28 / 10 \\
3 / 11\end{array}$ & & $\begin{array}{r}28 / 10 \\
3 / 11\end{array}$ & 2 & $3 / 11$ & & $\begin{array}{r}28 / 10 \\
3 / 11\end{array}$ & & & & \\
\hline $\begin{array}{l}\text { Total } \\
\text { Cycles }\end{array}$ & 29 & & 25 & & 10 & & 23 & & 11 & & 2 & \\
\hline
\end{tabular}

Total 100 cycles

* At $0.1 \mathrm{~Hz}$

$+\quad$ At $3 \mathrm{~Hz}$ 

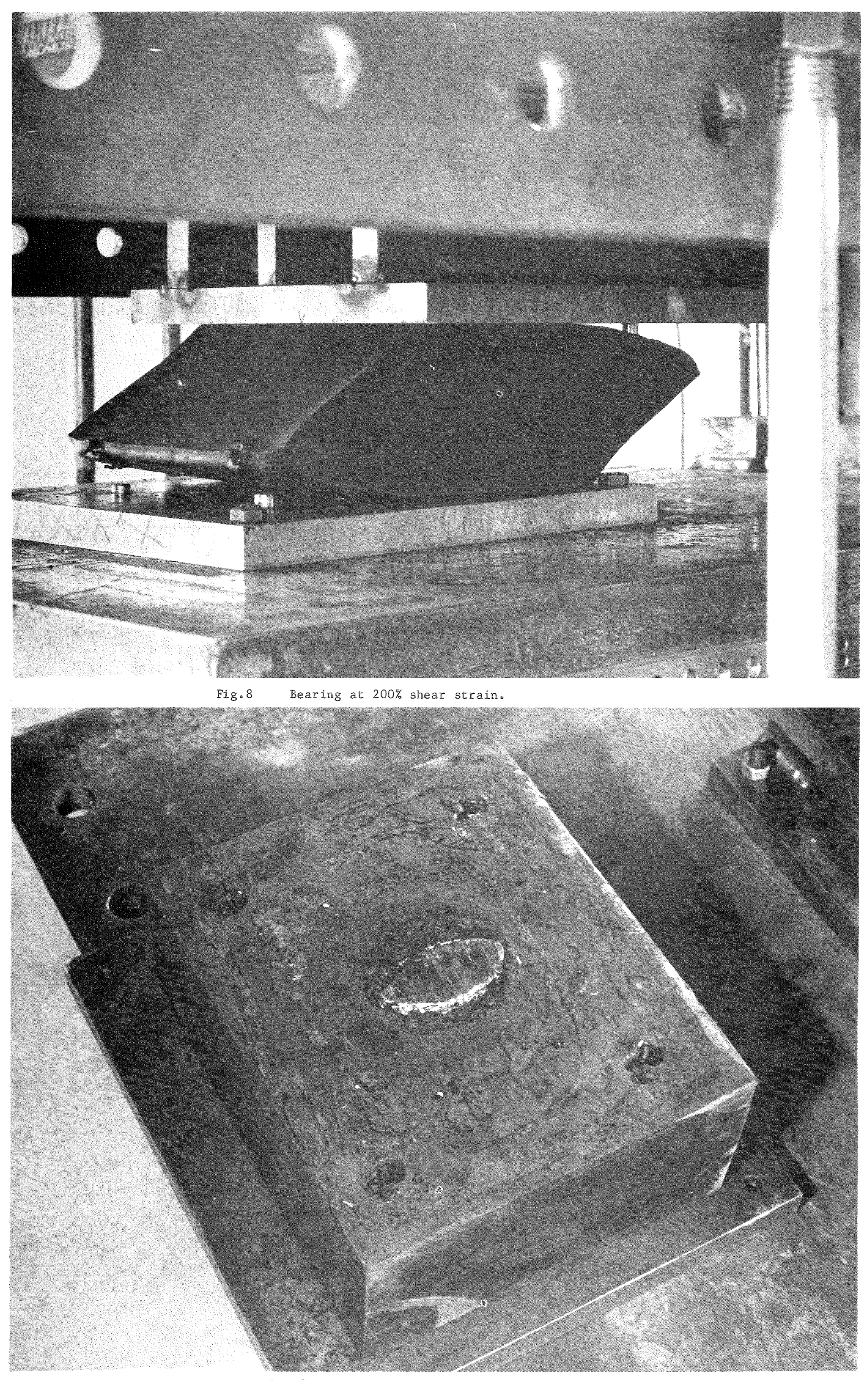

Fig.9 Bearing 150069/2 after testing. 

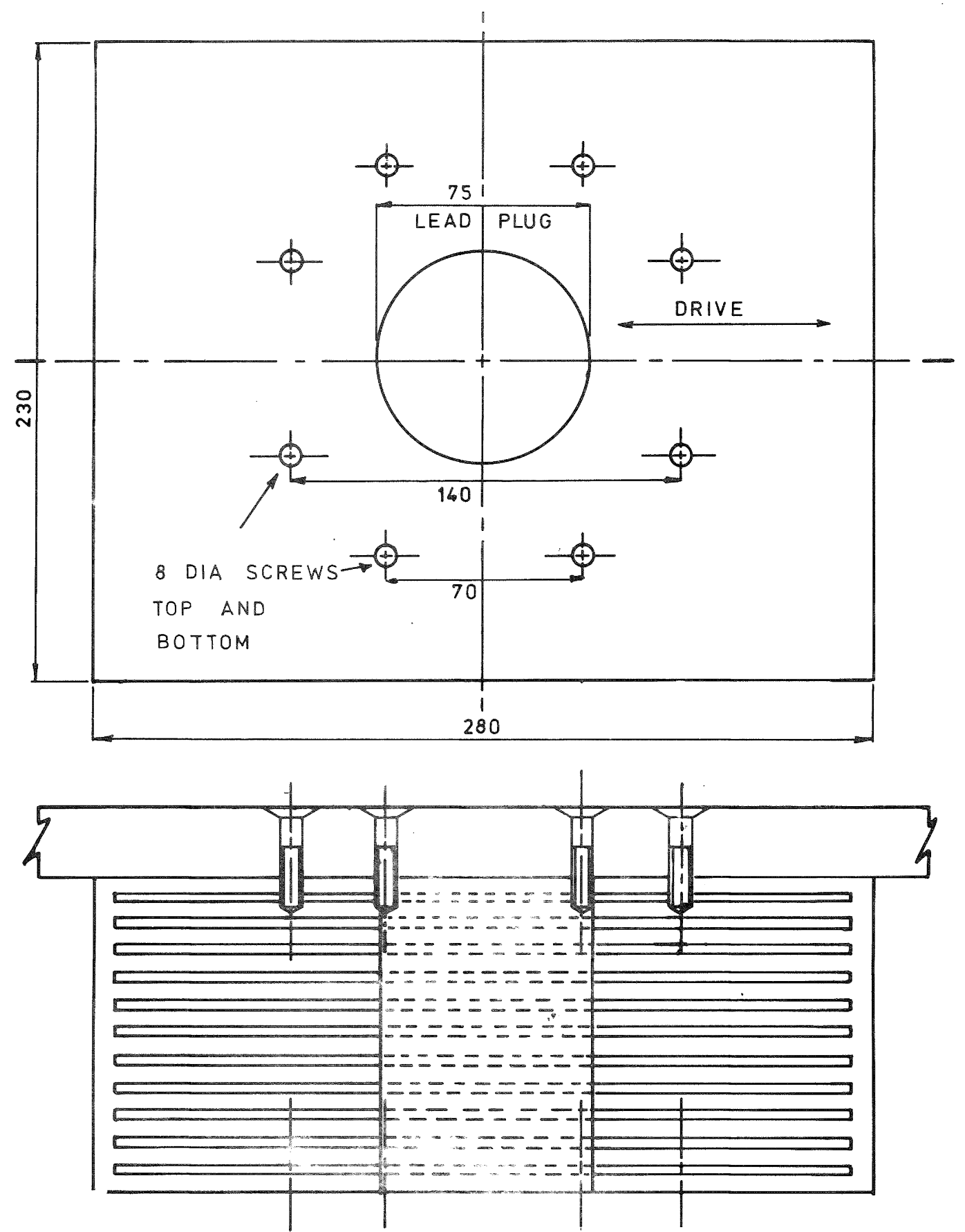

FIG 10 BEARING $150069 / 1$ SHOWING FIXING SCREWS TO PLATENS

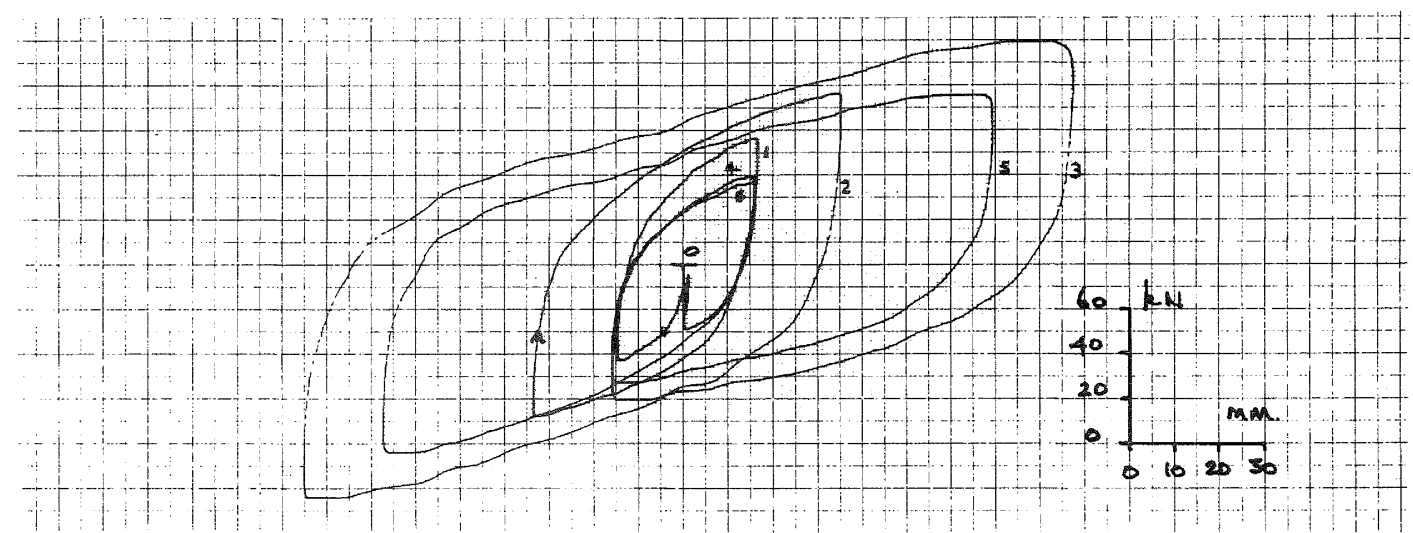

Fig. 11: Six cycle earthquake at $1 \mathrm{~Hz}$ for a peak strain of $\pm 125 \%$ in the rubber. Frequency $1 \mathrm{~Hz}$ (Bearing 150069/1) 


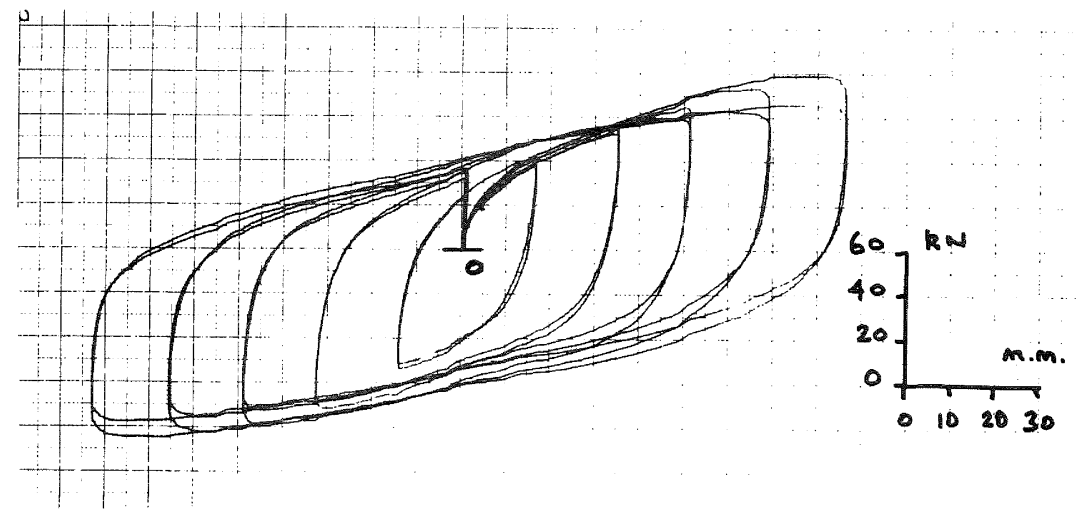

Fig.13: Shear force/displacement hysteresis loops for a load $280 \mathrm{kN}$ at $0.1 \mathrm{~Hz}$ (Bearing 150069/1)
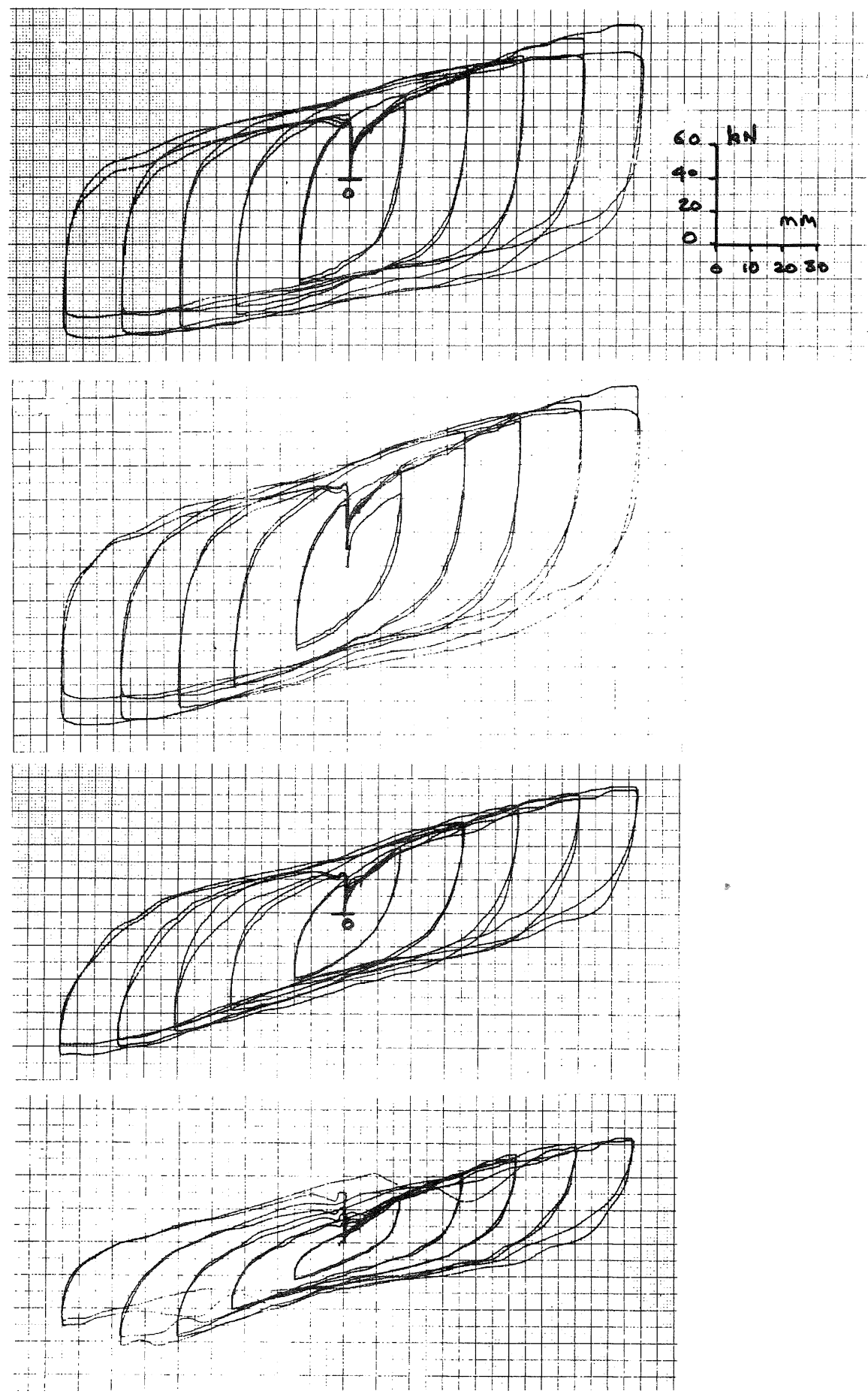

Fig.12: Shear force/displacement hysteresis loops at $1 \mathrm{~Hz}$ for vertical loads $450 \mathrm{kN}$ (top), $280 \mathrm{kN}, 105 \mathrm{kN}$ and $35 \mathrm{kN}$ (bottom) at $1 \mathrm{~Hz}$ (Bearing 150069/1) 
from the test machine and converted back to a spigoted connection for the remainder of the testing, with the four spigots on a 115 $\mathrm{mm}$ pitch circle diameter.

Six-cycle sequence: The object of this sequence was to find out how the bearing would behave when subjected to a large earthquake represented by six consecutive cycles of varying amplitude at $1 \mathrm{~Hz}$. The programme was set up on the Dartec block programmer as follows:

$\begin{array}{crr}\begin{array}{c}\text { Cycle (at } P_{50} \\ \text { vertical load) }\end{array} & \begin{array}{l}\text { Stroke } \\ ( \pm \mathrm{mm})\end{array} & \begin{array}{l}\text { Shear st } \\ \text { in rubber } \\ \left( \pm \frac{\circ}{0}\right)\end{array} \\ 1 & 17.5 & 25 \\ 2 & 35.0 & 50 \\ 3 & 87.5 & 125 \\ 4 & 17.5 & 25 \\ 5 & 70.0 & 100 \\ 6 & 17.5 & 25\end{array}$

The peak strain of $125 \%$ was chosen as previous tests indicated that this level of strain would not cause significant damage to the bearing and that further testing using the same bearing would be possible.

The sequence was carried out after an interval of five days following the previous testing which culminated in the two cycle tests to $\pm 200 \%$ strain; during this time the spigots were fitted to the platens. Initially the block programmer failed to function as desired and ten excursions were performed with strains up to $200 \%$ in the rubber in one direction only. However, within a few minutes the fault was corrected and the hysteresis loops shown in Figure 11 were obtained, apparently with no ill effects from the previous high strains imposed.

The hysteresis loops show that there is a good energy absorption for loop 3, which corresponds to a major excursion at the beginning of a large earthquake.

Thereafter, there is some drop in performance most likely due to heating of the lead, eg the depth of loop 5 for $\pm 100 \%$ shear strain is about $20 \%$ less than that for loop 3 at $\pm 125 \%$ shear strain. However, by the next day when further testing was carried out, the bearing had recovered.

Further two-cycle tests: Further two-cycle tests were carried out at vertical loads of $\mathrm{P}_{0}, \mathrm{P}_{50}, 0.375 \mathrm{P}_{50}$ and $0.125 \mathrm{P}_{50}$ at $1 \mathrm{~Hz}$ at the same time extending the strain range up to $\pm 125 \%$ strain in the rubber and plotting all the loops for a particular vertical load together on the XY plotter, rather than superimposing them later by tracing as previously (Figure 4 for bearing 150069/2), which had given rise to small inaccuracies in superimposing the origins of the curves. The tests also had the purpose of checking the performance of the bearings following the excursion to a nominal $\pm 200 \%$ strain and the six-cycle earthquake. At the lowest vertical load of $0.125 \mathrm{P}_{50}$ there was a tendency for the bearing to judder off its spigots, due to the lift at the bearing edges, which gave rise to the unevenness of the loops. Testing would not have been possible below this vertical load at the higher strains.
Comparing the results of the tests with those obtained previously, it can be concluded that, in spite of the higher strains and the previous history of testing up to $200 \%$ strain, the overall depth of the loops (Figure 12), as compared with those obtained previously (for example, Figure 4), was about the same, that is, there was no decrease in performance.

The tests for $\mathrm{P}_{50}$ were repeated at $0.1 \mathrm{~Hz}$ (Figure 13), at which frequency the overall depth of the loop decreased from $120 \mathrm{kN}$ at $1 \mathrm{~Hz}$ to $100 \mathrm{kN}$, that is, a reduction of about $16 \%$ in absorbed energy at the slower speed. Six percent of this reduction is due to the rate dependence of the rubber bearing (Figure 3 ) leaving a change of $10 \%$ for the plastic deformation of the lead. This reduction of 108 per decade change in rate is in good agreement with the previously determined value of 8\%(3). Tests at $3 \mathrm{~Hz}$ were tried but the pumps could not accurately follow the faster speed.

Sixty-cycle test: The previous programmed test of six sequential cycles at $1 \mathrm{~Hz}$ was too short in duration to typically represent the whole of an earthquake. Accordingly, another test of one minute duration was carried out, five minutes after completion of the previous test, with the following sequence of cycles at $1 \mathrm{~Hz}$ :

$\begin{array}{lll}\text { Cycle (at } P_{50} & \text { Stroke } & \text { Shear strain } \\ \text { vertical load) } & ( \pm \mathrm{mm}) & \text { in rubber } \\ & & \left( \pm \frac{\circ}{0}\right)\end{array}$

$\begin{array}{rrrr} & 1 & 17.5 & 25 \\ 2 & 35.0 & 50 \\ 3 & 87.5 & 125 \\ 4 & 15.0 & 21 \\ & & 70.0 & 100 \\ 5 & 20.0 & 29 \\ 6 & 5.0 & 7 \\ & 76.0 & 23 \\ & 8 & 32.0 & 46 \\ & 9 & 85.0 & 121 \\ 10 & 5.0 & 7 \\ 11 \text { to } 50 & \text { Repeat of cycles } \\ 51 \text { to } 60 & \text { 1 to } 10 & \end{array}$

Cycles 11 to 50 at the short stroke of $\pm 5 \mathrm{~mm}$ were intended to represent a period of comparative lull between the two main sequences of shocks represented by cycles 1 to 10 and 50 to 60 .

Results are given in Figure 14, which shows a set of loops for cycles 1 to 10 and a further set for cycles. 51 to 60 , with a few of the intermediate cycles of $\pm 5 \mathrm{~mm}$ also included.

The loops for cycles 1 to 10 show a marked deterioration from those in previous tests, as the overall depth at the axis of zero strain was $80 \mathrm{kN}$ for cycles 1 to 10 as compared with $120 \mathrm{kN}$ in previous tests (Figure 12). This deterioration is not surprising since the lead rubber bearing had before this test undergone many cycles at high strains. There was a further decrease for loops 51-60, where the loop depth was $72 \mathrm{kN}$. There was also some "pinching" of the loops, possibly indicating that some slack had developed in the pins keying the bearing to the top and bottom plates, which may have been caused by 
damage resulting from testing at light vertical loads.

It was concluded at this stage that there had been damage both to the lead plug and the shear pins, either arising from the large number of cycles that had been performed, or from the light-load tests carried out immediately before. It was decided, however, that testing would continue even though the lead-rubber bearing had now sur vived the equivalent of many major earthquakes.

120-cycle test: This test was carried out on the following day and was similar except that 100 cycles at $5 \mathrm{~Hz}$ at $\pm 5 \mathrm{~mm}$ deflection were introduced into the "lull" period to simulate more rapid ground shaking. The programme, of 40 seconds duration, was as follows:

Cycle (at $\mathrm{P}_{50}$ vertical load)

Stroke

$( \pm \mathrm{mm})$

Frequency $\mathrm{Hz}$

$$
1 \text { to } 10
$$

As in

previous test

11 to 110

$$
\pm 5 \mathrm{~mm}
$$

111 to 120 As cycles 1 to 10

The loop shapes were very similar to the previous test, with a further slight decrease in performance, the loop depth being $78 \mathrm{kN}$ for the first 10 cycles and $69 \mathrm{kN}$ for the last 10 .

Simulated earthquake: Finally, three days later, a programme simulating the effect of twice times the NS component of the 1940 El Centro earthquake on the bearings of a four-storey base-isolated building (Figure $15)$ was fed to the Dartec actuator. This gave a nominal peak strain in the rubber of $140 \%$. The result is shown in Figure 16 , which gives an overall impression of the effect of the earthquake on the bearing. The overall depth of the loops was $70 \mathrm{kN}$, as was obtained in the previous test. The numbered cycles show that the greatest loop area occurred early in the earthquake.

The whole earthquake was repeated six minutes later when there was a slight loss in loop area indicated by an overall depth of $68 \mathrm{kN}$ at the position of zero displacement.

\section{Appearance of lead plug following testing:} On completion of the above testing, the lead plug was pressed out of the bearing. Its appearance is shown in Figure 17. As would be expected, there are some fracture planes to be seen in the lead, while inspection of the rubber bearing revealed some ingress of lead into the rubber and local fracturing of the lead. This was, of course, after the bearing had been subjected to testing far in excess of its normal design life.

\section{VALUE OF BEARING SHEARING FORCE}

The derived values of the bearing shear force $\mathrm{Fa}$ at zero displacement on the hysteresis loop, derived from the initial twocycle tests on both bearings up to $\pm 100 \%$ strain in the rubber, when this value of strain had not previously been exceeded, are plotted in Figure 18 against the load on the bearing. The plotted values are derived from the hysteresis loops obtained after subtracting the frictional force arising from a single layer of rollers.

There is a drop in the value of $\mathrm{Fa}$ as the vertical load is reduced, as has already been reported in the literature(3). However in this instance, with the lead plug pressed, not cast, in the hole and a close spacing between the steel plates, the drop is not so severe that it cannot be allowed for in design; at $0.125 \mathrm{P}_{50}$ the value is about $70 \%$ that at $\mathrm{P}_{50} ; \mathrm{P}_{50}$ is the load to which bearings would normally be designed in the earthquake application. The value of the shear stress in the lead, $\sigma(\mathrm{Pb})$, is also plotted. This is obtained by subtracting the force appropriate to the rubber on its own (derived from Figure 3) from the force Fa for the complete bearing. The straightline portion of this curve has the equation

$$
\sigma(\mathrm{Pb})=11\left[1-\frac{0.1\left(\mathrm{P}_{50}-\mathrm{P}\right)}{\mathrm{P}_{50}}\right]
$$

$(\mathrm{MPa})$

for a vertical load $\mathrm{P}$ greater than $1 / 3 \quad \mathrm{P}_{50}$ and can be used to estimate Fa, knowing the properties of the rubber for a particular bearing.

It should be possible to improve the light load performance by increasing the area of lead, although previous research has indicated that there will be a limit to the increase that can be permitted as there must be sufficient bond strength in the rubber-steel sandwich to impart the shear deflections to the lead plug(1).

For a rocking building, where the bearings are designed to carry substantial loadings, there is a lesser problem caused by a tendency to uplift. On its compression side at least half the bearings will be fully operative in providing energy dissipation at any one time, while on the other side, where there is a tendency to uplift, the loss in energy dissipation will be at a maximum only instantaneously, typically at the peak of a sine curve.

\section{CONCLUSIONS}

1. Bearing $150069 / 2$ survived 75 cycles at strains in the rubber between 25\% and $200 \%$ while bearing $150069 / 1$ survived 100 such cycles and subsequent earthquake programmes. The performance indicates that strain up to $200 \%$ could be safely tolerated for the occasional very large earthquake.

At high strains the hysteresis loop is essentially a rectangle appropriate to the plastic shear of the lead plus the linear elastic slope of the rubber of the bearing with some softening at the corners of the loop.

2. The energy dissipated by the bearings decreased with the loading. The effect was shown to be almost instantaneous with a change in vertical pressure, that is, it depended on the elastic confining effect of the rubber. For load $P$ above $1 / 3 \mathrm{P}_{50}$ the corresponding shear stress in the lead was given by the equation 


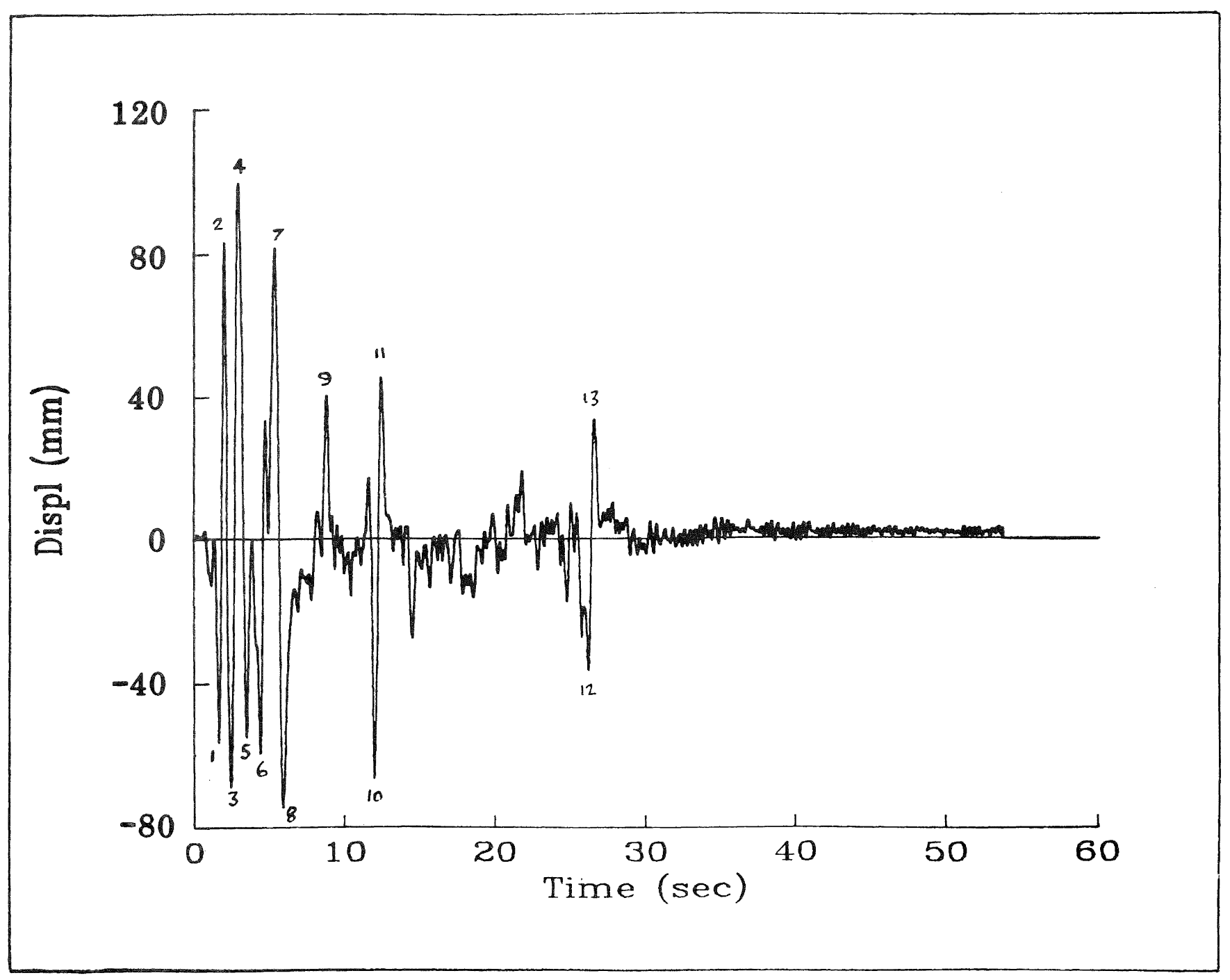

Fig. 15 The effect of $2 \times$ El Centro N.S. component on a base isolated building.

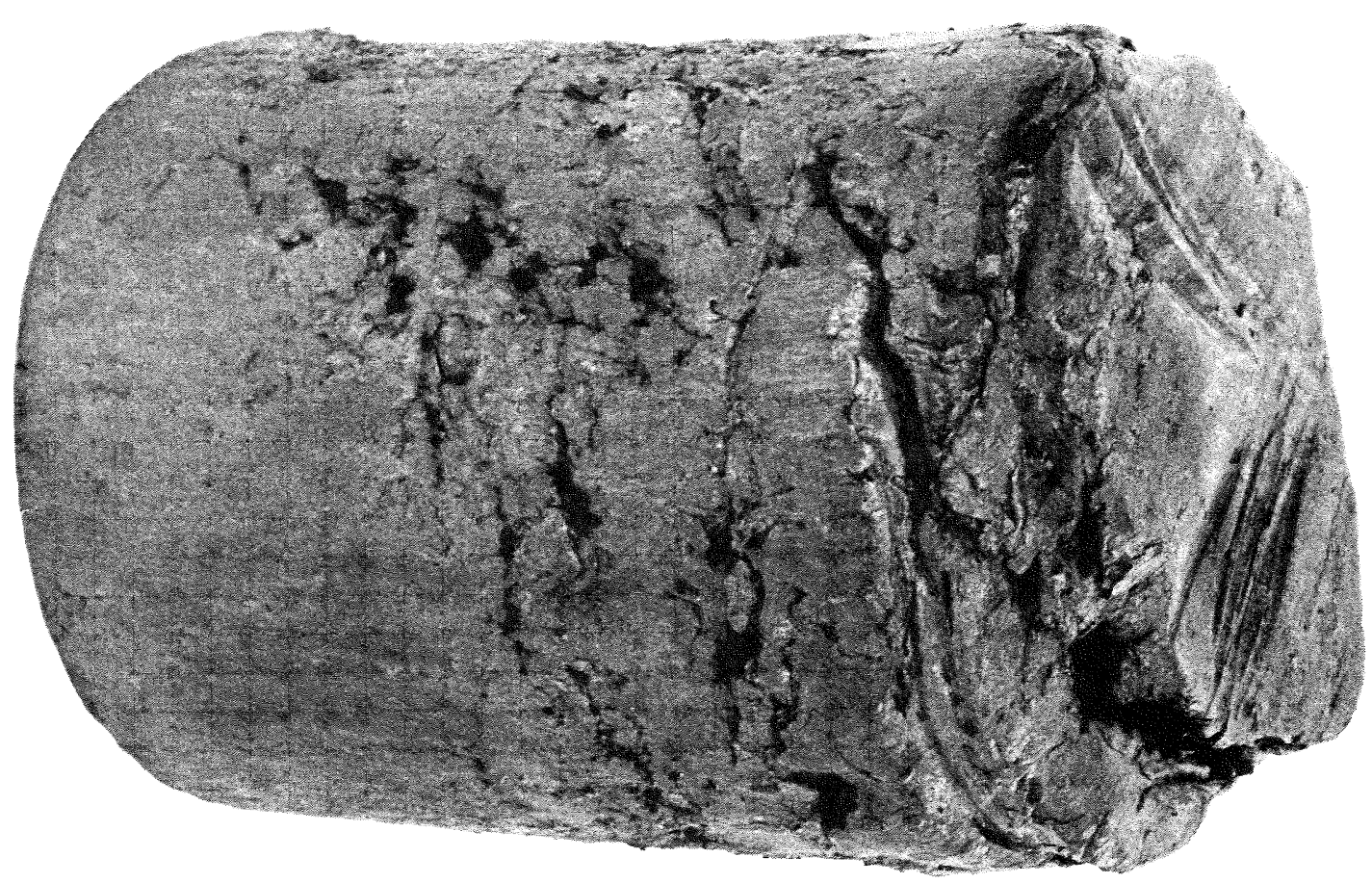

Fig. 17 Lead plug pushed out of bearing after testing. 


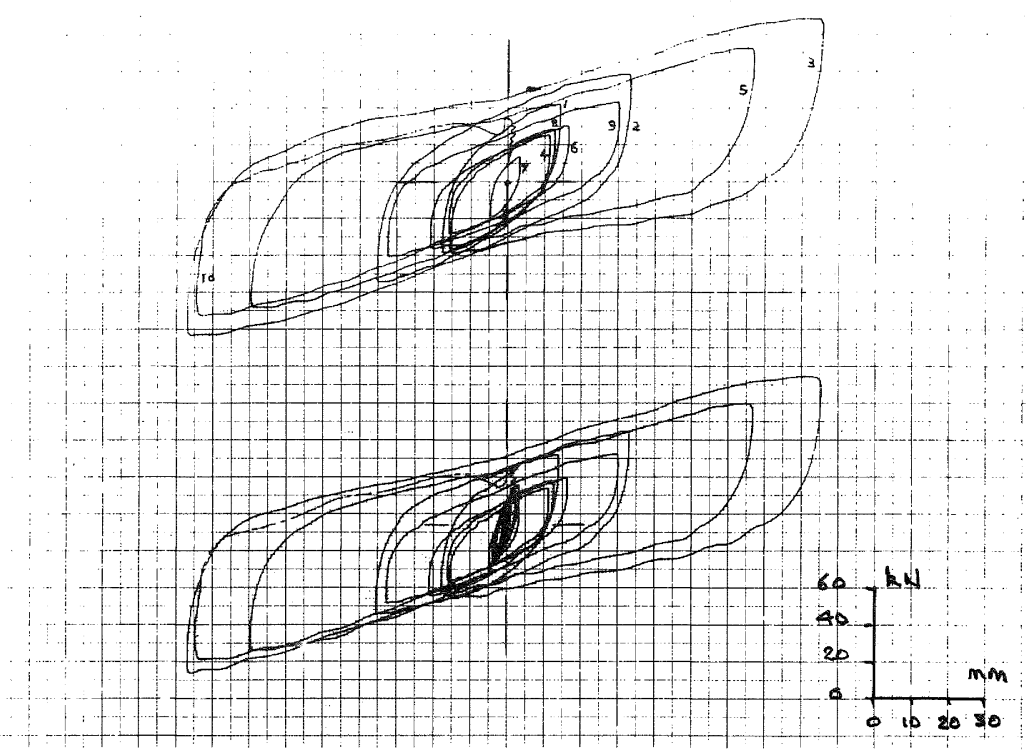

Fig.14: Shear force/displacement hysteresis loops for sixty cycle test. Upper loops first 10 cycles, lower loops last 10 cycles. Vertical load $280 \mathrm{kN}$ (Bearing $150069 / 1$ )

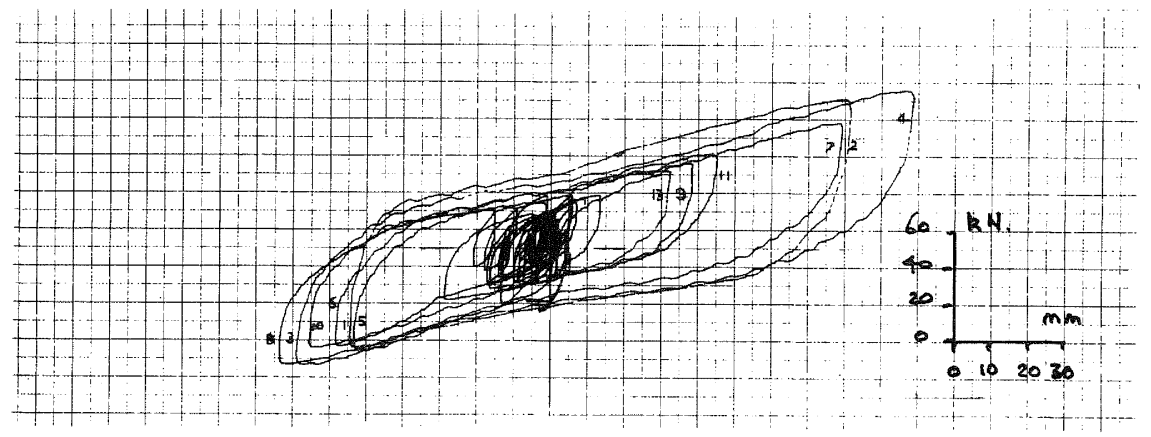

Fig.16: Shear force/displacement loops for earthquake input (Fig.15). Vertical load $280 \mathrm{kN}$ (Bearing 150059/1)

Vertical Load
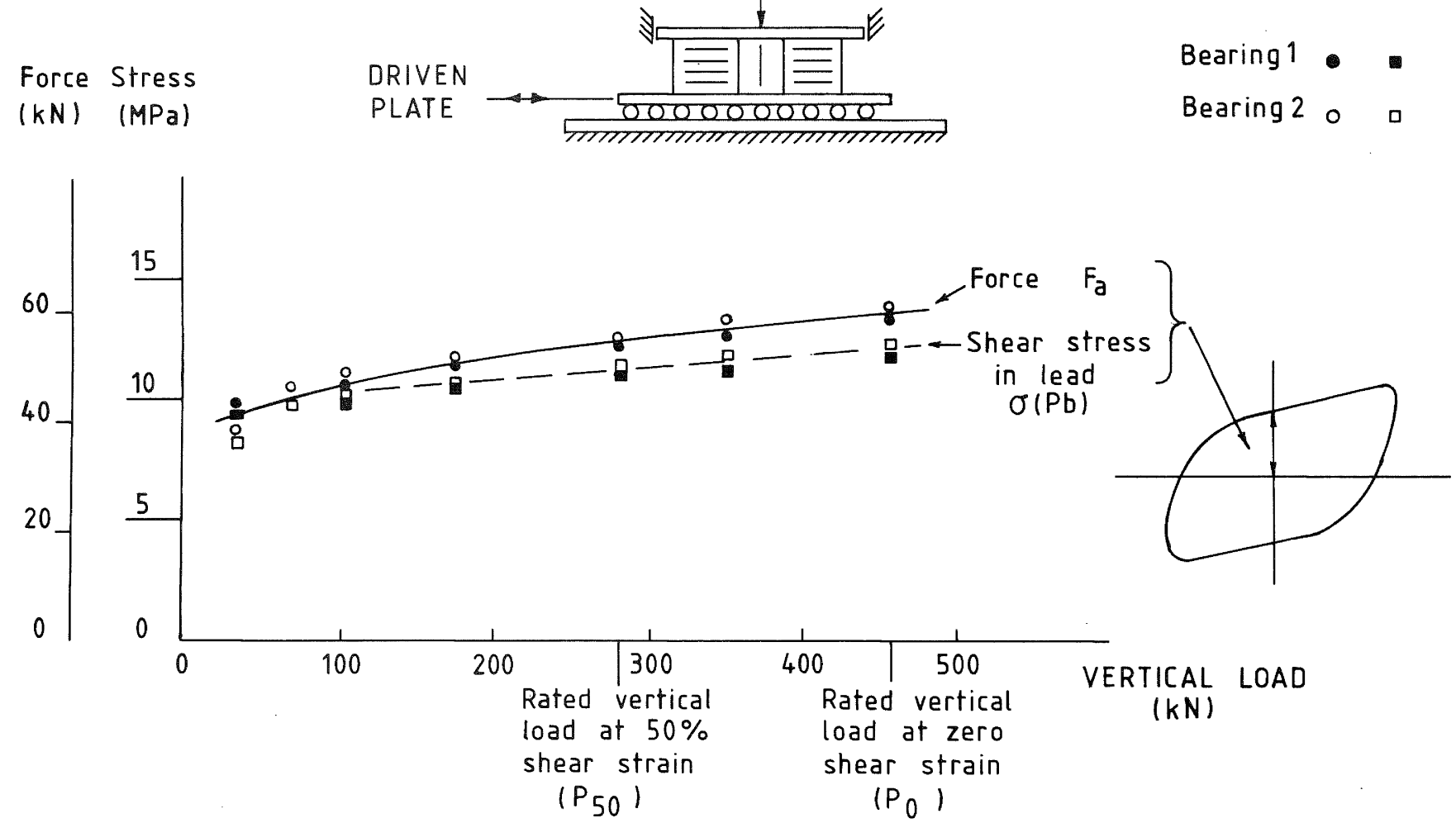

FIG 18 Shear force in bearing $F_{a}$, and shear stress in lead $\sigma(P b)$ at zero strain on hysteresis loop for 2 cycle tests 


$$
\sigma(\mathrm{Pb})=11\left[1-\frac{0.1\left(\mathrm{P}_{50}-\mathrm{P}\right)}{\mathrm{P}_{50}}\right](\mathrm{MPa})
$$

which can be used to estimate the shear force $\mathrm{Fa}$ in the bearing, when the properties of the rubber are established. Below $1 / 3 \mathrm{P}_{50}$, which may be a design load for some bridge bearings, the decrease in shear stress is greater, but can nevertheless be designed for.

3. There may also be a light load condition for some perimeter bearings of a baseisolated building as it tends to rock. This will only occur instantaneously, typically near the peak of a sine curve, and, as can be seen from Figure 17, the losses will not be appreciable, bearing in mind that they will be compensated for, to some extent, by increased energy dissipation from overloaded bearings on the other side of the building.

4. In the second bearing an attempt was made to improve the light load performance by screwing the machine platens to the first internal plate in the bearings, but no improvement in performance was noted.

5. Because of the tendency for the bearing edges to lift at high strains, spigots used to transfer load to the first internal plate in the bearing should be located near the centre of the bearing as close as possible to the lead plug.

6. The thin plates used at the top and bottom of the bearing allowed considerable elastic deformation without failure of the bearing. If thicker plates are used this deformation will be restricted, causing tearing of the rubber.

7. The two-cycle tests showed that provided there was an interval of a few minutes between experiments, the energy dissipating properties of the bearing are unchanged. However, five-cycle tests on one bearing showed that the loss in loop area increased to $40 \%$ after five cycles at $200 \%$ shear strain in the rubber, while a sixcycle test on the other bearing, to various strain levels up to $125 \%$, showed a $20 \%$ loss by the fifth cycle, although the properties were fully recoverable. The "fade" characteristic arises from the lead heating during plastic deformation and thereby causing a reduction in the shear stress required to plastically deform the lead.

8. The earthquake sequences confirmed the fade characteristic in that there was a $20 \%$ loss in area of a loop for a major cycle following the first in a sequence of six but that the loss was recovered after the earthquake.

9. Since a particular building is only likely to be subjected to a major earthquake about once a century, one way of carrying out proving tests would be to perform a simulated earthquake of, say, two minutes only, without previosly applying the very large number of individual twocycle tests. The true response of the bearing to the earthquake would then be obtained prior to any damage being incurred by repetitive testing. The amount of "fade" could be assessed by noting the loop area reduction for the recurrence of the same peak strain in the sequence.

\section{REFERENCES}

1. Robinson $\mathrm{W} \mathrm{H}$ and Tucker $\mathrm{A}$ G. $\mathrm{A}$ lead-rubber shear damper. Bulletin New Zealand National Society for Earthquake Engineering 10, 151-153, 1977.

2. Robinson $\mathrm{W} H$ and Tucker $A$. Test results for lead-rubber bearings for the William Clayton Building, Toe Toe and Waiotukupuna Bridges. Bulletin New Zealand National Society for Earthquake Engineering 14, 21-33, 1981 .

3. Robinson $\mathrm{W}$ H. Lead-rubber hysteretic bearings suitable for protecting structures during earthquakes. Earthquake Engineering and Struct Dyn Vol 10, 593-604, 1982 .

4. Skinner $R$ I, Tyler R G, Heine A J and Robinson $W \mathrm{H}$. Hysteretic dampers for the protection of structures from earthquakes. Bulletin New Zealand National Society for Earthquake Engineering Vol 13, No 1, 1980.

5. Megget L M. Analysis and design of a base-isolated reinforced concrete framed building. Bulletin New Zealand National Society for Earthquake Engineering, Vol 11, No 4, 1978.

6. Kelly J M and Hodder S B. Experimental study of lead and elastomeric dampers for base isolation systems. Report No UCB/EERC-81/16 College of Engineering, University of California. Berkeley, 1981.

7. Kelly J M. The economic feasibility of seismic rehabilitation of buildings by base isolation. Report No UCB/ EERC-83/01 College of Engineering, University of California, Berkeley. 1983.

8. Built $S$ M. Lead-rubber dissipation for the base isolation of bridge structures. Report No 289, School of Engineering, University of Auckland, 1982 .

9. Robinson $W H$ and Greenbank L R. Properties of an extrusion energy absorber. Bulletin New Zealand National Society for Earthquake Engineering 8 $287-291,1971$

10. Robinson $\mathrm{W} H$ and Greenbank $L$ R. An extrusion energy absorber suitable for the protection of structures during an earthquake. Earthquake Engineering and Struct Dyn 4, 251-259, 1976. 